\title{
Botany
}

\section{Plants that track the Sun}

\section{from Harry Smith}

THE facility with which heliotropic leaves and flowers turn to face the Sun has for so long been part of nature lore that it may well seem surprising to the casual observer that so little is known of the mechanisms of perception and response of foliar orientation. An even more puzzling problem of photoperception is posed by the so-called compass plants, whose leaves have a fixed orientation along the meridian. Our ignorance is particularly frustrating in view of the satisfying understanding of the ecological significance of these phenomena which has developed in recent years, as shown in a recent paper of Werk and Ehleringer ${ }^{1}$. They analysed the behaviour of Lactuca serriola, a common weed whose cauline leaves have laminae facing east-west. The ecological advantage of this strategy seems to lie in the decreased light interception at the middle of the day, which reduces leaf surface temperature by as much as $5^{\circ} \mathrm{C}$, a major factor in limiting water loss. Photosynthetic rates are high, however, in the morning and afternoon, when water relations are more favourable.

The opposite strategy - that of maximum interception of light - is favoured by plants whose leaves track the Sun with their laminae perpendicular to the direction of solar radiation. The increase in the daily rate of net photosynthesis due to such 'diaheliotropic' movements is considered to be of particular advantage in seedling establishment and for ephemeral or annual vegetation constrained to complete its life cycle quickly before the onset of long periods of drought or thermal stress ${ }^{2,3}$. Ehleringer and Forseth ${ }^{4}$ recognized solar tracking in plants of 16 families growing in the arid regions of the southwestern United States, including both $\mathrm{C} 3$ and $\mathrm{C} 4$ species. In terms of total daily photosynthetic photon fluence, they estimated diaheliotropic leaves to be 38 per cent more effective in light interception than were fixed horizontal leaves, and an amazing 167 per cent more effective than non-tracking vertical leaves of random azimuth ${ }^{4}$. Relating these values of potential photosynthesis to actual productivity indicates that diaheliotropism increases carbon assimilation by at least 30-40 per cent, principally by enhancing photosynthetic rates in the morning and evening, when solar elevation is low and plant-water relations are favourable. An intriguing example of the ecological advantage of heliotropism occurs with certain flowers in which solar tracking elevates the temperature within the floral parts, producing 'solar furnaces' which aid both pollination and seed development ${ }^{5,6}$.

The complement to diaheliotropism is paraheliotropism, in which leaf laminae are held parallel to the Sun's rays, ensuring minimum absorption of radiant energy and consequent reduction of the heat load on the leaf with obvious benefits in times of water stress ${ }^{7,8}$.

In contrast to the irreversible orientation of the leaves of compass plants - which is fixed during leaf development by a mechanism that seems to involve photoreception, since plants grown in the shade have randomly orientated leaves ${ }^{1}-$ the leaf movement of heliotropic plants is reversible. Unlike stem phototropism, it is not the result of asymmetric growth; in most cases the movements are caused by specialized pulvinal - or 'hinge' - cells situated at the bases of leaves and/or leaflets, although some petioles appear to have pulvinal characteristics along most or part of their length. Changes in the ionic relationships between the pulvinal cells and their neighbours result in rapid spatial variations in turgor throughout the pulvinus region, causing movement of the dependent lamina ${ }^{9}$. The perception problem, therefore, becomes one of understanding how the direction of the Sun's rays incident upon the leaf is transduced into internal signals which regulate the ionic characteristics of specific pulvinal cells.

The general characteristics of diaheliotropic movements are well-defined in a recent paper by Vogelmann and Bjorn on Lupinus succulentus ${ }^{10}$. Typically, when they irradiated a leaf with a beam of white light directed obliquely at the upper surface, leaf movement began 30-60 min later, and reached a maximum rate of about $15^{\circ}$ per hour. Importantly, irradiating the lower (abaxial) surface of the leaf caused no response. Using Lavatera cretica, Koller had previously shown experimental rates of movement of more than $90^{\circ}$ per hour, far greater than the minimum required to track the Sun ". It is also interesting that a beam directed from the base to the tip of the leaf causes it to rotate upwards, whilst the opposite orientation of the beam causes downward rotation; in both cases, the adaxial epidermis comes to lie perpendicular to the beam ${ }^{12}$.

The perception of vectorial stimuli by plants is a particularly perplexing problem. Haupt and Feinleib have put forward two possible scenarios: either each sensor cell perceives the direction of the stimulus and the resultant intracellular gradients are integrated within the organ during transduction, or different sensor cells are stimulated differently because of the directional nature of the stimulus and the intercellular gradient is transduced to the orientation response $^{13}$. For heliotropism it is not yet possible to distinguish between these two possibilities and a satisfactory hypothesis for vectorial photoperception does not exist.
To find even a promising idea it is necessary to go back 70 years to the work of Haberlandt ${ }^{14}$, who was far ahead of his time in so many fields of plant physiology. Studying the relationships between the structural anatomy of plant cells and their evident functions, he described the widespread occurrence of papillose epidermal cells - surface cells which are raised moreor-less into the shape of a dome but in which the inner walls are flat and parallel to the leaf surface. Such cells act as surface lenses and concentrate perpendicular light into a central illuminated zone of the inner wall, leaving the outer parts and the flanking walls comparatively dark. Haberlandt originally thought papillose epidermes concentrated light on to the photosynthetic mesophyll cells but later came to regard them as 'the optical senseorgans of foliage-leaves'14. By ingenious experiments on surgically removed epidermes he showed that bright spots could indeed be visualized in positions corresponding to the papillose cells, and he was even able to focus the image of a microscope stand using the particularly bulging cells of Anthurium warocqueanum. By wetting one portion of a heliotropic leaf with a thin film of water, separating it from the remaining dry portion by a black paper screen and exposing each to an oblique beam of light, Haberlandt showed that the leaf always orientated itself preferentially in response to the stimulus received by the dry region. This is exactly what would be predicted were the epidermal cells acting as condensing lenses. Oblique illumination of the epidermis results in a relative darkening of the central region of the inner wall and a relative brightening of part of the flanking regions - sufficient, perhaps, to estabish the intracellular gradient which may be the prelude to the movement of the leaf. Little modern evidence on the epidermal anatomy of solar-tracking leaves appears to exist, although the prevalence of papillose epidermes in petals has been highlighted by Kay et al. ${ }^{15}$ who see their importance more in terms of light reflection than light perception. Perhaps a return to the ideas and methods of Haberlandt would prove illuminating, in more ways than one.

1. Werk, K.S. \& Ehleringer, J. Pl. Cell Environ. 7, 81 (1984). . Mooney, H.A. \& Ehleringer, J.R. Pl. Cell Environ. 1. 307 (1978).

Shell, G.S.G. \& Lang, A.R.G. Agric. Metereol. 16, 16 (1976).

Ehleringer, J.R. \& Forseth, I. Science 210, 1094 (1980).

5. Kevan, P.G. Science 189, 723 (1975).

6. Kjellberg, B. et al. Oecologia 54, 10 (1982).

Begg, J.E. \& Torsall, B.W. Bull. R. Soc. N.Z. 12, 277 (1974)

8. Shackel, K.A.\& Hall, A.E. Aust. J. Pl. Physiol. 6, 265 (1979)

. Wainwright, C.N. Am. J. Bot. 64, 1032 (1977).

Vogelmann, T.C. \& Bjorn, L.O. Physiologia Pl. 59, 533 (1983).

Koller, D. Yb. Carnegie Instn Wash. 1980-1981, 72 (1981)

2. Schwartz, A. \& Koller, D. Pl. Physiol. 61, 924 (1978).

3. Haupt, W. \& Feinleib, M.E. Encycl. PI. Physiol. N.S 7,1 (1979).

4. Haberlandt, G. Physiological Plant Anatomy 4th Edn, 613 (1914)

5. Kay, Q.O.N., Daoud, H.S. \& Stirton, C.H. Bot. J. Linn. Soc. 83, 57 (1981).

Harry Smith is Professor of Botany at the University of Leicester, Leicester LEI $7 R H$. 